\title{
Issue of Waist Circumference for the Diagnosis of Metabolic Syndrome Regarding Arterial Stiffness: Possible Utility of a Body Shape Index in Middle- Aged Nonobese Japanese Urban Residents Receiving Health Screening
}

\author{
Daiji Nagayama $^{a, b}$ Yasuhiro Watanabe ${ }^{b}$ Takashi Yamaguchi $^{b}$ Kenji Suzuki ${ }^{c}$ \\ Atsuhito Saiki $^{b}$ Kentaro Fujishiro $^{c}$ Kohji Shirai ${ }^{d}$ \\ ${ }^{a}$ Department of Internal Medicine, Nagayama Clinic, Tochigi, Japan; ${ }^{b}$ Center of Diabetes, Endocrinology and \\ Metabolism, Toho University, Sakura Medical Center, Chiba, Japan; ' Japan Health Promotion Foundation, Tokyo, \\ Japan; ${ }^{\text {Department }}$ of Internal Medicine, Mihama Hospital, Chiba, Japan
}

\section{Keywords}

A body shape index - Waist circumference - Metabolic syndrome - Visceral adiposity · Cardio-ankle vascular index · Cardiovascular disease

\begin{abstract}
Introduction: Abdominal obesity as a risk factor for diagnosing metabolic syndrome (MetS) is evaluated using waist circumference (WC), although WC does not necessarily reflect visceral adiposity. This cross-sectional study aimed to clarify whether replacing WC with "A Body Shape Index (ABSI)," an abdominal obesity index, in MetS diagnosis detects individuals with arterial stiffening assessed by cardio-ankle vascular index (CAVI). Methods: A retrospective cross-sectional study was conducted in 46,872 Japanese urban residents (median age 40 years) who underwent health screening. Exclusion criteria were current treatments and a past history of cardiovascular disease (CVD). The Japanese, International Diabetes Federation, and NCEP-ATPIII criteria were used to diagnose MetS. High CAVI was defined as CAVI $\geq 9$.0. Results: $C A V I$ correlated positively with $A B S I(\beta=0.127)$, but negatively with WC ( $\beta=-0.186)$, independent of age, sex, systolic blood
\end{abstract}

karger@karger.com www.karger.com/ofa

Karger $\frac{1}{\%}$
(C) 2022 The Author(s)

Published by S. Karger AG, Basel

This is an Open Access article licensed under the Creative Commons Attribution-NonCommercial-4.0 International License (CC BY-NC) (http://www.karger.com/Services/OpenAccessLicense), applicable to the online version of the article only. Usage and distribution for commercial purposes requires written permission. pressure, fasting plasma glucose, and high-density lipoprotein--cholesterol. Receiver operating characteristic (ROC) analysis showed that $A B S I$ had a stronger contribution to high CAVI (area under the ROC curve $[A \cup C]=0.730$ ) than WC (AUC $=0.595)$ and body mass index (AUC $=0.520$ ). ABSI $\geq 0.080$ was defined as abdominal obesity based on the results of ROC analysis for high CAVI and estimated glomerular filtration rate $<60 \mathrm{~mL} / \mathrm{min} / 1.73 \mathrm{~m}^{2}$. Logistic regression analysis revealed that replacing high WC with $A B S I \geq 0.080$ in MetS diagnosis enhanced the detection of subjects with high CAVI. Discussion/Conclusion: Use of ABSI can detect subjects with arterial stiffening, which may lead to efficient stratification of CVD risk. Further studies are needed to confirm whether MetS diagnosis using ABSI predicts CVD morbidity and mortality.

(c) 2022 The Author(s).

Published by S. Karger AG, Basel

\section{Introduction}

In patients with metabolic syndrome (MetS), visceral fat accumulation plays an essential role in the development of multiple cardiovascular disease (CVD) risks in- 
cluding elevated blood pressure (BP), glucose intolerance, and dyslipidemia $[1,2]$. Several epidemiological studies have demonstrated that MetS increases the risk of not only all-cause mortality but also CVD morbidity and mortality [3-5]. In the last 2 decades, the concept of MetS has been established, and various diagnostic criteria of MetS have been published by several academic societies, such as the National Cholesterol Education ProgramAdult Treatment Panel III (NCEP-ATPIII) [6], International Diabetes Federation (IDF) [7], and the Japanese Society of Internal Medicine [8]. However, the validity of these criteria is controversial. Sundström et al. [9] claimed that MetS does not necessarily predict CVD risk above and beyond its individual components. In addition, Reaven [10] emphasized that there are many non-MetS patients who are clearly at higher risk of CVD than MetS patients.

Arterial stiffness reflects vascular aging and reduced elasticity of the artery, and is used as a predictor of CVDs [11]. Pulse wave velocity (PWV) is a typical index of systemic arterial stiffness. However, PWV is not reproducible because it essentially depends on the BP at the time of measurement [12]. Cardio-ankle vascular index (CAVI) was developed to reflect the stiffness of the arterial tree from the origin of the aorta to the ankle, independent of BP at the time of measurement $[13,14]$. CAVI has been reported to be associated positively with a number of CVD risk factors [15-17], severity of CVD [18], and future CVD events [19]. Besides, we reported that body mass index (BMI) is inversely related to CAVI [20], even though increase in BMI contributes to the incidence of obesity-related metabolic disorders. European Association for the Study of Obesity (EASO) restructured the definition of obesity in International Classification of Diseases-11th revision and proposed the concept of adiposity-based chronic disease (ABCD). It emphasized 3 aspects of adiposity: total amount, distribution, and function of adipose tissue [21]. Moreover, it is generally accepted that obesity is classified into intra-abdominal fat obesity (visceral fat obesity) and extra-abdominal fat obesity (subcutaneous fat obesity). The former is also called "malignant obesity" because it is associated with various metabolic diseases, so-called MetS [22]. We have previously reported the association of CAVI with an abdominal obesity index [23] and that visceral fat reduction is directly related to reduced CAVI [24], suggesting that CAVI reflects vascular toxicity caused by visceral fat accumulation. These findings infer that CAVI can discriminate between malignant and nonmalignant obesity. On the other hand, MetS diagnosed by the current criteria containing waist

Utility of ABSI for MetS Diagnosis circumference (WC) is not necessarily associated with systemic arterial stiffening assessed by CAVI [25-28]. This finding seems to be consistent with the inverse association of CAVI with BMI and the imprecision of MetS as a CVD risk, as described earlier. We thus hypothesized that this incongruous phenomenon may be attributed to the uncertainty of WC as a predictor of visceral fat accumulation.

Currently, visceral fat area at the umbilical level is measured by computed tomography and is generally considered the gold standard for quantification of visceral fat. However, computed tomography is expensive and not always available is smaller clinical settings, making it difficult to use in routine clinical practice. Therefore, many abdominal obesity indices using anthropometric measurements have been established. "A Body Shape Index (ABSI)" is calculated by dividing WC by an allometric regression of weight and height [29], and is probably the only BMI-independent abdominal obesity index $[23,30]$. ABSI reflects visceral fat accumulation well [31,32], and is suitable in screening at-risk populations [33]. We have reported that increased ABSI reflects not only severity of metabolic disorders, but also systemic arterial stiffening indicated by high CAVI in Japanese general population [23]. Furthermore, a large European cohort study has also reported that ABSI predicts all-cause and CVD mortality with linear association, rather than U- or J-shaped association seen in BMI, WC, or waist-to-height ratio [30]. With the above background, we sought to investigate whether there is room for improvement of the current diagnostic criteria for MetS.

\section{Materials and Methods}

Subjects and Design

We performed a retrospective cross-sectional study in Japanese urban residents who underwent health screening between April 2010 and March 2019 in Japan.

\section{Data Collection and MetS Criteria}

The population-based sample used in the present analysis comprised 76,720 Japanese subjects residing in major cities nationwide who participated in the CVD and cancer screening program organized by the Japan Health Promotion Foundation. Participants were volunteers who were not paid and were not recruited for this study (unlike subjects of a clinical trial). Since CAVI is modified by treatments for metabolic disorders and CVD, subjects taking any medication and/or having a history of heart disease, treatment for hypertension, stroke, diabetes, nephritis, or gout were excluded. We finally enrolled 46,872 subjects in the present study.

All parameters were assessed using standardized methods. Height and body weight (BW) were measured, and BMI was cal- 
culated as follows: BW (kg) divided by square of height $(\mathrm{m})$. WC was measured horizontally at the level of the umbilicus, with the participant standing and arms hanging relaxed. ABSI was calculated by the following formula: $\mathrm{ABSI}=\mathrm{WC} / \mathrm{BMI}^{2 / 3} \times$ height $^{1 / 2}[29]$. Currently, an online calculator implementing the derived formulas for anthropometric risk indicators including ABSI is freely available at https://nirkrakauer.net/sw/ari-calculator.html.

Blood samples were collected from the antecubital vein in the morning after $12 \mathrm{~h}$ of fasting to measure fasting plasma glucose (FPG), triglycerides (TG), and high-density lipoprotein--cholesterol (HDL-C). Low-density lipoprotein-cholesterol (LDL-C) was calculated using Friedewald formula: LDL-C $=$ total cholesterol (TC) - (HDL-C) - (TG/5). Since this formula is not valid for patients with TG $\geq 400 \mathrm{mg} / \mathrm{dL}$ [34], subjects with TG $\geq 400 \mathrm{mg} / \mathrm{dL}$ (1.2\% of all participants) were excluded from the analysis of LDLC. All assays were performed according to standard procedures. Estimated glomerular filtration rate (eGFR) was calculated by the following equation of the Japanese Society of Nephrology [35]:

$\operatorname{eGFR}\left(\mathrm{mL} / \mathrm{min} / 1.73 \mathrm{~m}^{2}\right)=194 \times$ creatinine $\mathrm{e}^{-1.094} \times$ age $^{-0.287}$

$(\times 0.739$ if female $)$

Declined renal function was defined as eGFR $<60 \mathrm{~mL} / \mathrm{min} / 1.73$ $\mathrm{m}^{2}$. Exclusion criteria were, as abovementioned, current medication use, and a history of CVD, stroke, hypertension, diabetes, dyslipidemia, nephritis, or gout at the time of examination. However, those who were newly diagnosed with one or more CVD risk factors such as dyslipidemia, hypertension, and impaired fasting glucose according to the examination results were included in analysis. CVD risks were determined according to the diagnostic criteria for MetS described below.

In the present study, the following 3 diagnostic criteria for MetS were adopted: the criteria developed by the Japanese Committee for the Diagnostic Criteria of MetS [8], the NCEP-ATPIII criteria [6], and the IDF criteria [7]. To diagnose MetS, high WC is a necessary criterion in the Japanese and IDF criteria, and a sufficient condition in NCEP-ATPIII criteria [5].

Initially, the threshold for FPG in NCEP-ATP III was $110 \mathrm{mg} /$ dL. Later, however, American Diabetes Association lowered the threshold of FPG used to identify individuals with impaired fasting glycemia from $110 \mathrm{mg} / \mathrm{dL}$ to $100 \mathrm{mg} / \mathrm{dL}$, and the NCEP-ATP III followed suit [36].

\section{Measurement of CAVI and BP}

Arterial stiffness was assessed by CAVI using VaSera VS-1500 (Fukuda Denshi Co. Ltd, Tokyo, Japan). CAVI was calculated according to the following formula: CAVI $=a\{(2 \rho / \Delta \mathrm{P}) \times \ln (\mathrm{Ps} / \mathrm{Pd})$ $\left.\mathrm{PWV}^{2}\right\}+b$, where Ps is systolic BP; Pd is diastolic BP; $\Delta \mathrm{P}$ is Ps $\mathrm{Pd} ; \rho$ is blood density; $\mathrm{PWV}$ is cardio-ankle PWV, and a and $b$ are constants.

The cuffs were wrapped around the upper arms and ankles of subjects in supine position with the head in the midline position. Examination was started after 5 min of rest. When detecting pulse waves in the upper arms and ankles with cuffs, a low cuff pressure of 30-50 mm Hg was used to minimize the influence of cuff pressure on hemodynamics. BP was measured from the upper arm cuffs. PWV was determined by dividing the arterial length by the time taken for the pulse wave to propagate from the aortic valve to the ankle and was measured using the upper arm and ankle cuffs. Because CAVI may be falsely low in patients with severe arterial occlusive disease, we excluded subjects with an ankle-brachial in- dex lower than 0.90 . The details of CAVI have been reported previously [13].

\section{Statistical Analysis}

All data are expressed as median (interquartile range). The SPSS software (version 11.5, Chicago, IL, USA) was used for statistical processing. Mann-Whitney U test or Fisher's exact test was performed to analyze sex difference in clinical variables or prevalence of major CVD risk factors. The relationship between CAVI and clinical variables was analyzed by multiple regression analysis. Sensitivity and specificity of each body adiposity index in predicting high CAVI were analyzed using conventional receiver operating characteristic (ROC) curves. Analysis of variance followed by Bonferroni multiple comparison test was used to compare age-adjusted CAVI according to MetS criteria using WC or ABSI as the abdominal obesity index, by sex. Bivariate logistic regression analysis was performed to examine the contribution of variables to high CAVI. We arbitrarily defined "high CAVI" as equal to or higher than 9.0 in all participants, corresponding substantially to the cutoff value for the presence of coronary artery stenosis $[14,18]$. In all comparisons, 2 -sided $p$ values $<0.05$ were considered statistically significant.

\section{Results}

\section{Clinical and Biochemical Characteristics of Male and} Female Participants

In this study, a total of 46,872 Japanese urban residents (24,417 males and 22,455 females, median age 40 years, median BMI $21.8 \mathrm{~kg} / \mathrm{m}^{2}$ ) were screened. Table 1 compares the clinical characteristics of male and female participants.

Compared with females, males had significantly higher BMI, WC, CAVI, BP, FPG, and TG; and lower age, ABSI, HDL-C, and eGFR. The proportions of subjects with $\mathrm{BMI} \geq 25 \mathrm{~kg} / \mathrm{m}^{2}$, newly diagnosed hypertension, impaired fasting glycemia, dyslipidemia, and MetS diagnosed according to 3 criteria were higher in males, whereas the proportion of older age (age $\geq 65$ years) was higher in females. The frequency of declined renal function was the same in both sexes.

\section{Correlation of CAVI with Clinical Variables Analyzed by Multiple Regression Model}

Next, we examined the factors associated with CAVI. Table 2 summarizes the results of multiple regression analysis for the correlation between CAVI and main clinical variables. TG was omitted because of intraclass correlation with HDL-C (Spearman's correlation coefficient $[\rho]=-0.516)$. BMI was also omitted because of intraclass correlation with WC $(\rho=0.877)$. 
Table 1. Clinical and biochemical characteristics of male and female participants

\begin{tabular}{|c|c|c|c|c|}
\hline & $\begin{array}{l}\text { Total } \\
(N=46,872)\end{array}$ & $\begin{array}{l}\text { Male } \\
(N=24,417)\end{array}$ & $\begin{array}{l}\text { Female } \\
(N=22,455)\end{array}$ & $p$ value \\
\hline Age, years & $40(32-52)$ & $39(32-50)$ & $41(33-54)$ & $<0.001$ \\
\hline BW, kg & $59.1(51.0-68.4)$ & $66.8(60.7-74.0)$ & $51.2(46.8-56.4)$ & $<0.001$ \\
\hline $\mathrm{BMI}, \mathrm{kg} / \mathrm{m}^{2}$ & $21.8(19.8-24.2)$ & $22.9(21.2-25.2)$ & 20.5 (18.9-22.6) & $<0.001$ \\
\hline WC, m & $0.788(0.722-0.856)$ & $0.824(0.764-0.885)$ & $0.745(0.692-0.810)$ & $<0.001$ \\
\hline CAVI & $7.3(6.7-7.9)$ & $7.3(6.8-8.0)$ & $7.2(6.7-7.9)$ & $<0.001$ \\
\hline $\mathrm{SBP}, \mathrm{mm} \mathrm{Hg}$ & $120(110-130)$ & $124(115-132)$ & $114(106-125)$ & $<0.001$ \\
\hline $\mathrm{DBP}, \mathrm{mm} \mathrm{Hg}$ & $70(63-78)$ & $74(66-80)$ & $67(60-74)$ & $<0.001$ \\
\hline $\mathrm{FPG}, \mathrm{mg} / \mathrm{dL}$ & $84(79-90)$ & $86(81-91)$ & $82(78-88)$ & $<0.001$ \\
\hline $\mathrm{LDL}-\mathrm{C}, \mathrm{mg} / \mathrm{dL}$ & $119(97-142)$ & $122(101-144)$ & $114(94-139)$ & $<0.001$ \\
\hline $\mathrm{HDL}-\mathrm{C}, \mathrm{mg} / \mathrm{dL}$ & $65(54-77)$ & $58(49-69)$ & $72(62-84)$ & $<0.001$ \\
\hline $\mathrm{BMI} \geq 25 \mathrm{~kg} / \mathrm{m}^{2}, \%$ & 18.9 & 26.5 & 10.5 & $<0.001^{*}$ \\
\hline \multicolumn{5}{|l|}{ High WC, \% } \\
\hline$W C \geq 85(\mathrm{~m})$ or $90(\mathrm{f}) \mathrm{cm}$ & 23.4 & 38.5 & 6.9 & $<0.001^{*}$ \\
\hline$W C \geq 90(\mathrm{~m})$ or $80(\mathrm{f}) \mathrm{cm}$ & 24.3 & 20.6 & 28.4 & $<0.001^{*}$ \\
\hline$W C \geq 102(\mathrm{~m})$ or $88(\mathrm{f}) \mathrm{cm}$ & 6.3 & 3.3 & 9.5 & $<0.001^{*}$ \\
\hline$A B S I \geq 0.080, \%$ & 33.9 & 27.1 & 41.4 & $<0.001^{*}$ \\
\hline $\mathrm{CAVI} \geq 9.0, \%$ & 7.3 & 8.0 & 6.4 & $<0.001^{*}$ \\
\hline $\mathrm{BP} \geq 130 / 85 \mathrm{~mm} \mathrm{Hg}, \%$ & 27.3 & 35.2 & 18.6 & $<0.001^{*}$ \\
\hline $\mathrm{FPG} \geq 100 \mathrm{mg} / \mathrm{dL}, \%$ & 6.6 & 9.2 & 3.8 & $<0.001^{*}$ \\
\hline $\mathrm{FPG} \geq 110 \mathrm{mg} / \mathrm{dL}, \%$ & 2.5 & 3.6 & 1.2 & $<0.001^{*}$ \\
\hline $\mathrm{HDL}-\mathrm{C}<40 \mathrm{mg} / \mathrm{dL}, \%$ & 3.5 & 6.1 & 0.7 & $<0.001^{*}$ \\
\hline $\mathrm{TG} \geq 150 \mathrm{mg} / \mathrm{dL}, \%$ & 15.3 & 23.6 & 6.3 & $<0.001^{*}$ \\
\hline
\end{tabular}

Data are presented as median (IQR) or percentage of patients. Metabolic dyslipidemia includes TG $\geq 150$ and/or HDL-C $<40 \mathrm{mg} / \mathrm{dL}$. BW, body weight; BMI, body mass index; WC, weight circumference; ABSI, a body shape index; CAVI, cardio-ankle vascular index; SBP, systolic blood pressure; DBP, diastolic blood pressure; FPG, fasting plasma glucose; LDL-C, low-density lipoprotein-cholesterol; HDL-C, high-density lipoprotein-cholesterol; TG, triglyceride; eGFR, estimated glomerular filtration rate; MetS, metabolic syndrome; IDF, International Diabetes Federation; NCEP-ATPIII, National Cholesterol Education Program-Adult Treatment Panel III; IQR, interquartile range. Mann-Whitney U test and * Fisher's exact test were used to compare male and female subjects.

Age was a major independent predictor for CAVI $(\beta$ coefficient $=0.733$ ). Additionally, CAVI was associated positively with male sex, systolic BP, FPG and negatively with HDL-C and eGFR. As for the abdominal obesity indies, ABSI was associated positively with CAVI ( $\beta$ coefficient $=0.135)$, whereas WC was associated negatively with CAVI ( $\beta$ coefficient $=-0.186)$, independent of cardiometabolic factors.
Discriminatory Powers of 3 Body Adiposity Indices for High CAVI ( $\geq 9.0)$

Furthermore, we examined the contribution of body adiposity index to high CAVI in all participants. ROC analyses were used to evaluate the discriminatory power of 3 body adiposity indices; ABSI, WC, and BMI, for high CAVI (Fig. 1). 
Table 2. Correlation of CAVI with clinical variables analyzed by multiple regression model

\begin{tabular}{lllr}
\hline Variables & Standard error & $\beta$ coefficient & $p$ value \\
\hline Male & 0.006 & 0.138 & $<0.001$ \\
Age, years & $<0.000$ & 0.733 & $<0.001$ \\
WC, m & 0.038 & -0.186 & $<0.001$ \\
ABSI & 0.782 & 0.135 & $<0.001$ \\
SBP, $\mathrm{mm} \mathrm{Hg}$ & $<0.001$ & 0.114 & $<0.001$ \\
FPG, $\mathrm{mg} / \mathrm{dL}$ & $<0.001$ & 0.030 & $<0.001$ \\
$\mathrm{HDL}-\mathrm{C}, \mathrm{mg} / \mathrm{dL}$ & $<0.001$ & -0.013 & $<0.001$ \\
LDL-C, mg/dL & $<0.001$ & 0.007 & 0.013 \\
eGFR, $\mathrm{mL} / \mathrm{min} / 1.73 \mathrm{~m}^{2}$ & $<0.0001$ & -0.031 & $<0.001$ \\
\hline
\end{tabular}

Model $R^{2}=0.695, p<0.001$. WC, weight circumference; $\mathrm{ABSI}$, a body shape index; $\mathrm{CAVI}$ cardio-ankle vascular index; SBP, systolic blood pressure; FPG, fasting plasma glucose; LDL-C, low-density lipoprotein-cholesterol; HDL-C, high-density lipoprotein-cholesterol; eGFR, estimated glomerular filtration rate.
ABSI showed the highest discriminatory power (area under ROC curve [AUC]: 0.730, 95\% confidence interval $[\mathrm{CI}]: 0.721-0.738, p<0.001)$ compared to WC (AUC: $0.595,95 \%$ CI: $0.586-0.604, p<0.001$ ) and BMI (AUC: 0.520 , 95\% CI: $0.510-0.529, p<0.01)$. We previously reported that the cutoff value of ABSI estimated by Youden Index $J$ to predict high CAVI was 0.080 (sensitivity 0.675, specificity 0.630) in all subjects [37]. ROC analyses by sex found that the cutoff values were 0.079 (AUC: $0.723,95 \%$ CI: $0.713-0.733, p<0.001$ ) in males and 0.081 (AUC: $0.725,95 \%$ CI: $0.715-0.734, p<0.001$ ) in females [23]. Additionally, in this study, the ROC analysis revealed that the cutoff value of ABSI for declined renal function was 0.080 (AUC: $0.623,95 \%$ CI: $0.607-0.639, p<0.001$ ), and that there was no significant sex difference (data not shown). Consequently, high ABSI was defined as higher than or equal to 0.080 regardless of sex, and this cutoff value was used to substitute high $\mathrm{WC}$ as the index of abdominal obesity in MetS diagnosis.

\section{Proposal to Replace High WC by High ABSI as}

Criterion of Abdominal Obesity in MetS Diagnosis

Details of 3 representative diagnostic criteria for MetS (Japanese, IDF, and NCEP-ATPIII) are shown in Table 3. All the diagnostic criteria use WC as the abdominal obesity index, although the cutoff values are different among the 3 . We proposed to change the criterion of abdominal obesity from high WC to ABSI $\geq 0.080$ in both sexes for all 3 diagnostic criteria. Furthermore, we examined whether there is a difference in CAVI level when MetS is diagnosed with criteria using ABSI (ABSI-MetS) compared with conventional criteria using WC (WCMetS).

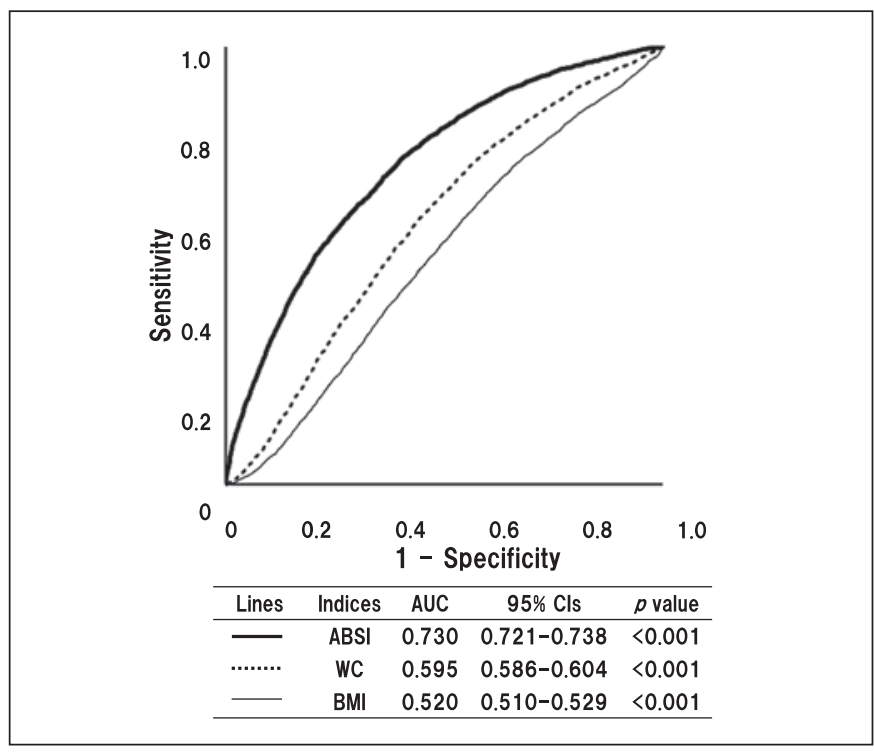

Fig. 1. Discriminatory powers of 3 body adiposity indices for high CAVI ( $\geq 9.0)$. Curves represent ROC analyses for discriminating the probability of high CAVI ( $\geq 9.0)$. CAVI, cardio-ankle vascular index; ROC, receiver operating-characteristics; WC, weight circumference; BMI, body mass index.

\section{Comparison of Age-Adjusted CAVI according to MetS}

\section{Criteria}

We examined the differences in age-adjusted CAVI when MetS was diagnosed with the 3 diagnostic criteria using WC or ABSI as the abdominal obesity index (Fig. 2). For all 3 diagnostic criteria; Japanese, IDF and NCEPATPIII, age-adjusted CAVI was almost the same in subjects with and those without MetS diagnosed using WC- 
Table 3. Proposal to replace high WC by high ABSI as the criterion of abdominal obesity in the diagnosis of MetS

\begin{tabular}{|c|c|c|c|}
\hline $\begin{array}{l}\text { Definition of MetS } \\
\text { Components }\end{array}$ & (1) + any 2 or more of (2) to (4) & $(1)+$ any 2 or more of (2) to (5) & 3 or more of (1) to (5) \\
\hline Hypertension & (2) $\mathrm{SBP} \geq 130 \mathrm{~mm} \mathrm{Hg}$ and/or DBP & (2) $\mathrm{SBP} \geq 130 \mathrm{~mm} \mathrm{Hg}$ and/or DBP & (2) $\mathrm{SBP} \geq 130 \mathrm{~mm} \mathrm{Hg}$ and/or DBP \\
\hline Dyslipidemia & $\begin{array}{l}\text { (4) } \mathrm{TG} \geq 150 \mathrm{mg} / \mathrm{dL} \text { and/or HDL-C } \\
<40 \mathrm{mg} / \mathrm{dL}\end{array}$ & (4) $\mathrm{TG} \geq 150 \mathrm{mg} / \mathrm{dL}$ & (4) $\mathrm{TG} \geq 150 \mathrm{mg} / \mathrm{dL}$ \\
\hline & & $\begin{array}{l}\text { (5) } \mathrm{HDL}-\mathrm{C}<40 \mathrm{mg} / \mathrm{dL} \text { (males), }<50 \mathrm{mg} / \mathrm{dL} \\
\text { (females) }\end{array}$ & $\begin{array}{l}\text { (5) } \mathrm{HDL}-\mathrm{C}<40 \mathrm{mg} / \mathrm{dL} \text { (males), } \\
<50 \mathrm{mg} / \mathrm{dL} \text { (females) }\end{array}$ \\
\hline
\end{tabular}

WC, weight circumference; ABSI, a body shape index; SBP, systolic blood pressure; DBP, diastolic blood pressure; FPG, fasting plasma glucose; LDL-C, lowdensity lipoprotein-cholesterol; HDL-C, high-density lipoprotein-cholesterol; TG, triglyceride; MetS, metabolic syndrome; IDF, International Diabetes Federation; NCEP-ATPIII, National Cholesterol Education Program-Adult Treatment Panel III.

MetS, but was remarkably higher in subjects with MetS than in those without MetS diagnosed using ABSI-MetS. In other words, the adoption of ABSI as an index of abdominal obesity was associated with higher value of CAVI in MetS patients.

\section{Bivariate Logistic Regression Models for High CAVI}

( $\geq 9.0)$ in Each MetS Criterion

Finally, we used logistic regression models to examine whether the contribution of MetS to high CAVI would be different if WC was replaced by ABSI in the diagnostic criteria (Table 4). The following MetS criteria were tested: Japanese (models 1 and 4), IDF (models 2 and 5), and NCEP-ATPIII (models 3 and 6). WC was used as the abdominal obesity index in models 1,2, and 3; and ABSI in models 4,5 , and 6 . The following factors, which have been reported to contribute to CAVI independent of MetS components, were adopted as confounders: sex, old age, declined renal function, and hyper-LDL cholesterolemia $[15,23,38]$.

MetS had an independent association with high CAVI across all diagnostic criteria. Concurrently, male sex, older age, chronic kidney disease, and hyper-LDL cholesterolemia each contributed to high CAVI. MetS diagnosed by ABSI-MetS showed larger odds ratios versus WCMetS with no overlap of 95\% CI in Japanese and IDF criteria. However, only in NCEP-ATPIII (models 3 and 6), the $95 \%$ CIs of WC-MetS and ABSI-MetS overlapped slightly (1.89-2.56 vs. $2.54-3.20)$.

\section{Discussion}

In this cross-sectional study conducted in a real-world Japanese population, CAVI correlated positively with ABSI, whereas CAVI correlated negatively with WC. Particularly, the association of ABSI with CAVI was independent of age, sex, systolic BP, FPG, and HDL-C in multiple regression analysis. Furthermore, ABSI had a remarkably stronger contribution to high CAVI $(\geq 9.0)$ than WC and BMI. We then defined ABSI $\geq 0.080$ as abdominal obesity based on the results of ROC analysis for discrimination of high CAVI and declined renal function. Logistic regression analysis revealed that replacing high WC with ABSI $\geq 0.080$ in the MetS diagnostic criteria enhanced the detection of MetS subjects with high CAVI in the Japanese and IDF diagnostic criteria. The strength of this study was to demonstrate that subjects with systemic arterial stiffening are more likely to be detected if ABSI is adopted to diagnose MetS in large-scale health screening.

Noninvasive clinical tools to assess vascular function have been developed and used to assess functional vascular damage and severity of atherosclerosis [39]. Flow-mediated dilation, the standard tool used to assess vascular endothelial function, has been known to correlate positively with BMI in healthy young adults [40]. This finding corroborates with reports of an inverse relationship between CAVI and BMI in the general Japanese and Chinese population [20,41,42]. Together, these studies suggest that BW gain per se may include a vasoprotective change of body composition in some individuals. In support of this paradoxical finding, it has been reported that 


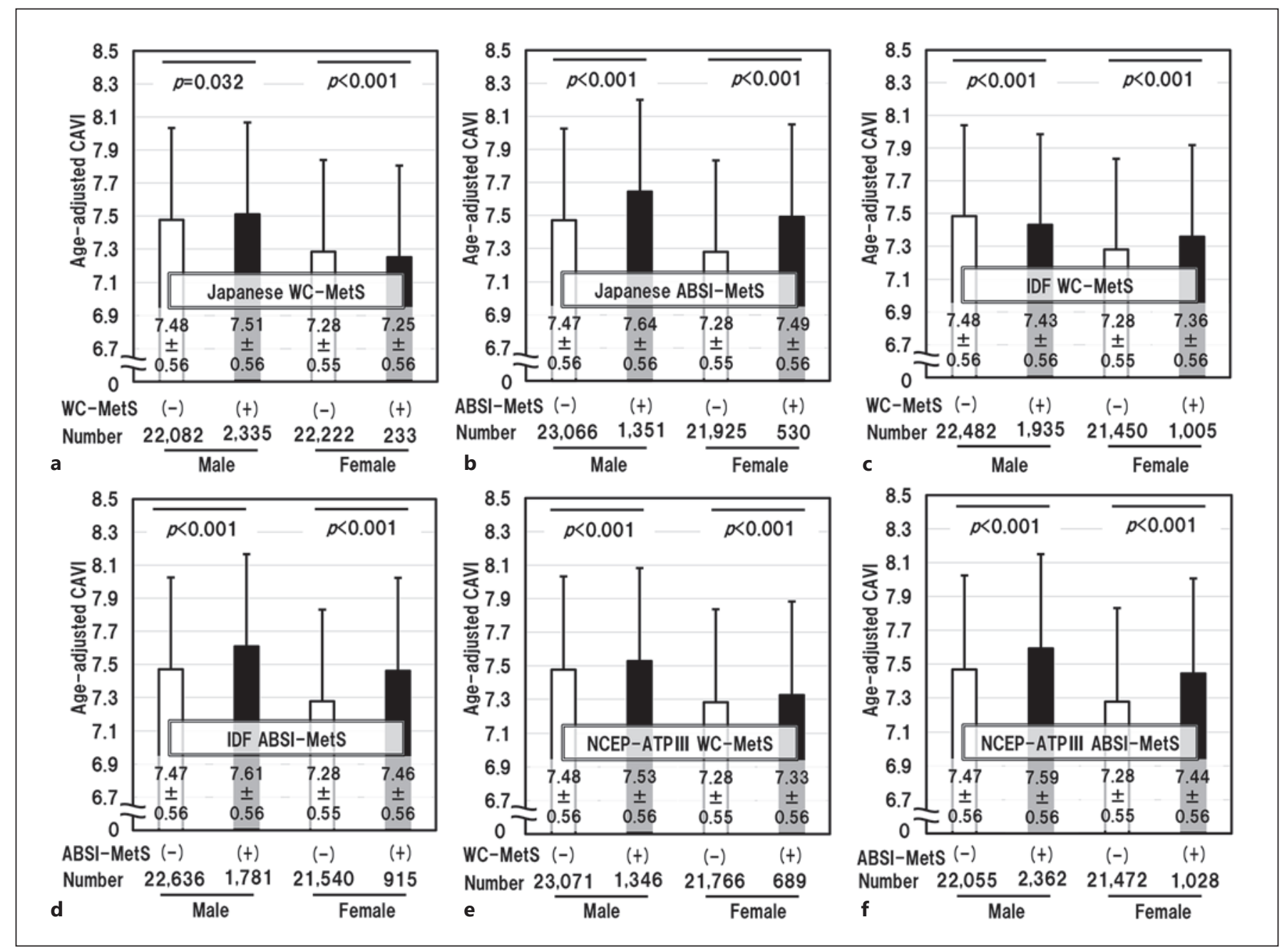

Fig. 2. Differences in age-adjusted CAVI according to different MetS diagnostic criteria using WC (WC-MetS) or using ABSI (ABSI-MetS) as the visceral obesity index. WC-MetS (a) and ABSIMetS (b) diagnosed by Japanese criteria. WC-MetS (c) and ABSIMetS (d) diagnosed by IDF criteria. WC-MetS (e) and ABSI-MetS (f) diagnosed by NCEP-ATPIII criteria. Data are presented as mean \pm SD. One-way ANOVA followed by Bonferroni multiple

when accompanied by obesity, the risk of all-cause or CVD mortality in MetS patients may be reduced to the same level as in non-MetS individuals [43]. In other words, BMI is not necessarily efficient for stratification of CVD risks; because of the obesity paradox that increased BMI may potentially reflect vasoprotective body composition. On the other hand, abdominal obesity, the underlying cause of MetS, is generally evaluated using WC. However, since WC correlates closely with BMI, it is difficult to distinguish between the 2 as epidemiological risk factors $[23,44]$. In fact, our data showed that WC corre- comparison tests were used for statistical analysis. CAVI, cardioankle vascular index; ROC, receiver operating characteristics; MetS, metabolic syndrome; ABSI, a body shape index; ANOVA, analysis of variance; IDF, International Diabetes Federation; NCEP-ATPIII, National Cholesterol Education Program-Adult Treatment Panel III; WC, weight circumference.

lated negatively with CAVI, contrary to ABSI (Table 2). The use of high WC as one of the MetS diagnostic criteria therefore inherently includes the obesity paradox, which may lead to the detection of individuals without systemic arterial stiffening. Although it is clear that visceral/ectopic fat accumulation is a major contributor to CVD risk beyond BMI [21], it remains difficult to implement fat distribution assessment into clinical practice.

The findings observed in the present study are also consistent with long-term follow-up studies showing that ABSI is a better predictor of long-term prognosis than 


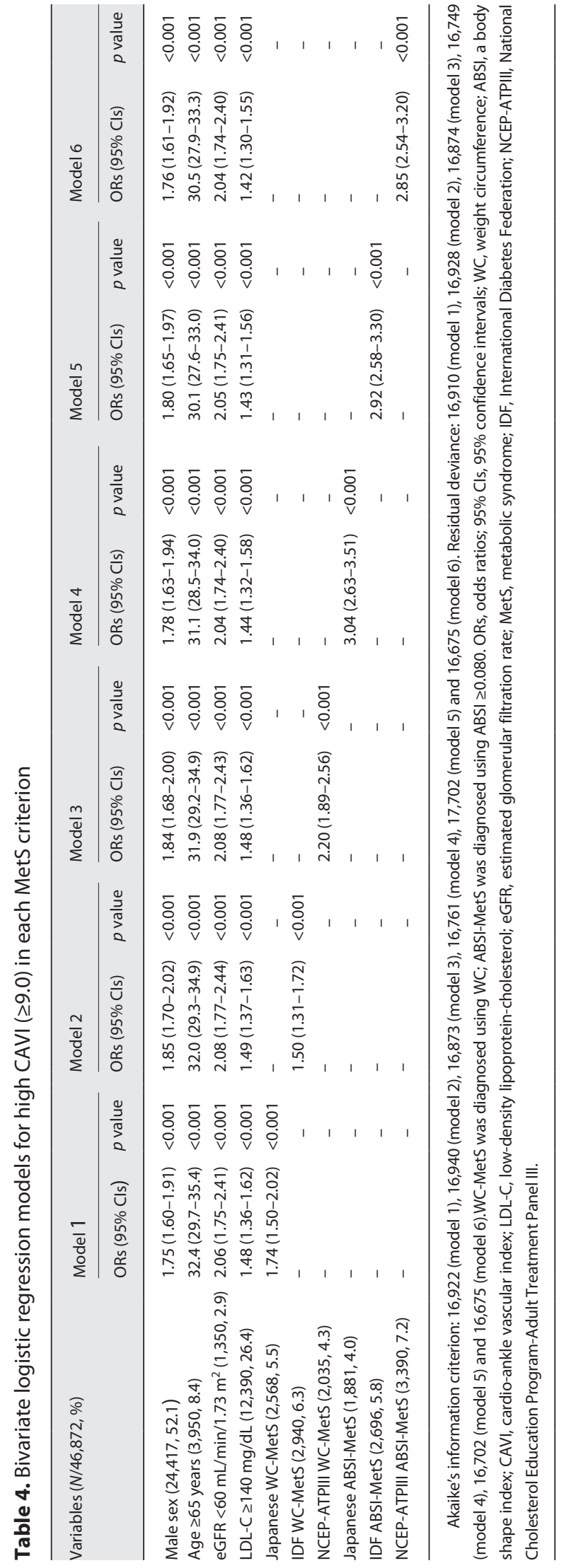

Utility of ABSI for MetS Diagnosis
BMI or WC $[30,45]$. The reason is that ABSI correlates with CAVI, and high CAVI is a predictor of CVD morbidity and mortality $[14,28]$. Furthermore, studies have shown that reducing BW, especially visceral fat, can decrease CAVI in obese patients with metabolic disorders $[24,28]$, and therapeutic intervention that reduces CAVI may prevent future CVD events [46]. It is therefore reasonable to consider that in patients diagnosed with MetS according to criteria using ABSI, weight reduction therapy can be expected to improve CVD outcome through decreasing CAVI. In addition, not only BMI but also WC shows U- or J-shaped association with all-cause or CVD mortality, whereas ABSI exhibits positive linear relationship $[47,48]$. Setting the cutoff value of obesity index that has a U- or J-shaped relationship with mortality risk leads to inaccurate assessment of the target population. Therefore, the use of abdominal obesity indices such as ABSI for MetS diagnosis may be rational to detect individuals with "malignant obesity" who require early therapeutic intervention. Future studies are needed to confirm whether MetS diagnosis using ABSI predicts morbidity and mortality, and whether therapeutic interventions that reduce ABSI improve prognosis.

As shown in Table 1, the incidence of abdominal obesity in females deviated significantly between $W C \geq 90 \mathrm{~cm}$ (6.9\%) and ABSI $\geq 0.080$ (41.4\%) in this study. However, WC reflects mainly subcutaneous fat rather than visceral fat in females; thus, estimation of abdominal obesity using WC may underestimate the accumulation of visceral fat [49]. The relatively high diagnostic rate of abdominal obesity by ABSI therefore does not necessarily mean overdiagnosis of abdominal obesity by ABSI. In addition to the high sensitivity in predicting abdominal obesity, the advantage of ABSI is the strong involvement in systemic arterial stiffening.

The limitation of this study is the cross-sectional nature, which cannot address causal relation or direction of the impact of body adiposity index on CAVI. Additionally, our findings may not be generalized to other ethnic groups. For example, the predictive ability of ABSI for the occurrence of diabetes was generally better than that of BMI, but predictive level of ABSI varied among different ethnicities [50]. In addition, most of the participants in this study were nonelderly and had no metabolic disorders. Due to the nature of the health screening program implemented, only $8.4 \%$ of the subjects were over 65 years of age. In future, it is necessary to verify whether the significance of ABSI-MetS criteria can be ensured for other ethnic groups of the elderly with metabolic disorders. 


\section{Conclusion}

In the present study, we examined whether using ABSI instead of WC as one of the diagnostic criteria for MetS detects individuals with systemic arterial stiffening assessed by CAVI. Based on the results, we proposed replacement of WC by ABSI in the diagnosis of MetS and discussed the issues of using WC as one of the diagnostic criteria of MetS.

In conclusion, the application of ABSI to the diagnosis of MetS can detect individuals with systemic arterial stiffening, which may allow efficient stratification of CVD risk. Further studies are needed to confirm whether MetS diagnosis using ABSI as the abdominal obesity index predicts CVD morbidity and mortality.

\section{Acknowledgments}

We would like to thank all the staff members in our departments who contributed to this study.

\section{Statement of Ethics}

This study was approved by the Institutional Review Board and Ethics Committee of Sakura Hospital, School of Medicine, Toho University (No. S19006). Written informed consent for the examinations was obtained from the participants, and informed consent was obtained by opt out method.

\section{Conflict of Interest Statement}

The authors declared no conflict of interest.

\section{Funding Sources}

No funding was provided for this study.

\section{Author Contributions}

All authors made substantial contributions to conception and design, acquisition of data, or analysis and interpretation of data; took part in drafting the article or revising it critically for important intellectual content; gave final approval of the version to be published; and agree to be accountable for all aspects of the work.

\section{Data Availability Statement}

The data that support the findings of this study are not publicly available due to their containing information that could compromise the privacy of research participants. Further inquiries can be directed to the corresponding author.

\section{References}

1 Eckel RH, Grundy SM, Zimmet PZ. The metabolic syndrome. Lancet. 2005;365(9468): 1415-28.

2 Matsuzawa Y, Funahashi T, Nakamura T. The concept of metabolic syndrome: contribution of visceral fat accumulation and its molecular mechanism. J Atheroscler Thromb. 2011; 18(8):629-39.

3 Isomaa B, Almgren P, Tuomi T, Forsén B, Lahti K, Nissén M, et al. Cardiovascular morbidity and mortality associated with the metabolic syndrome. Diabetes Care. 2001;24:683-9.

4 Ninomiya T, Kubo M, Doi Y, Yonemoto K, Tanizaki Y, Rahman M, et al. Impact of metabolic syndrome on the development of cardiovascular disease in a general Japanese population: the Hisayama study. Stroke. 2007; 38(7):2063-9.

5 Hata J, Doi Y, Ninomiya T, Tanizaki Y, Yonemoto K, Fukuhara M, et al. The effect of metabolic syndrome defined by various criteria on the development of ischemic stroke subtypes in a general Japanese population. Atherosclerosis. 2010;210(1):249-55.

6 Expert Panel on Detection, Evaluation, and Treatment of High Blood Cholesterol in
Adults. Executive summary of the third report of the National Cholesterol Education Program (NCEP) expert panel on detection, evaluation, and treatment of high blood cholesterol in adults (adult treatment panal III). JAMA. 2001;285:2486-97.

7 Alberti KG, Zimmet P, Shaw J. Metabolic syndrome: a new world-w ide definition. A consensus statement from the International Diabetes Federation. Diabet Med. 2006;23(5):469-80.

8 Matsuzawa Y. Metabolic syndrome: definition and diagnostic criteria in Japan. J Atheroscler Thromb. 2005;12:301.

9 Sundström J, Vallhagen E, Risérus U, Byberg L, Zethelius B, Berne C, et al. Risk associated with the metabolic syndrome versus the sum of its individual components. Diabetes Care. 2006;29(7):1673-4.

10 Reaven GM. The metabolic syndrome: is this diagnosis necessary? Am J Clin Nutr. 2006; 83(6):1237-47.

11 Mitchell GF, Hwang SJ, Vasan RS, Larson MG, Pencina MJ, Hamburg NM, et al. Arterial stiffness and cardiovascular events: the Framingham heart study. Circulation. 2010; 121(4):505-11.
12 Shirai K, Song M, Suzuki J, Kurosu T, Oyama $\mathrm{T}$, Nagayama D, et al. Contradictory effects of $\beta 1$ : and $\alpha 1$-aderenergic receptor blockers on cardio-ankle vascular stiffness index (CAVI) -the independency of CAVI from blood pressure. J Atheroscler Thromb. 2011;18:49-55.

13 Shirai K, Utino J, Otsuka K, Takata M. A novel blood pressure independent arterial wall stiffness parameter; cardioankle vascular index (CAVI). J Atheroscler Thromb. 2006;13:101-7.

14 Saiki A, Ohira M, Yamaguchi T, Nagayama D, Shimizu N, Shirai K, et al. New horizons of arterial stiffness developed using cardio-ankle vascular index (CAVI). J Atheroscler Thromb. 2020;27(8):732-48.

15 Nagayama D, Watanabe Y, Saiki A, Shirai K, Tatsuno I, et al. Lipid parameters are independently associated with cardio-ankle vascular index (CAVI) in healthy Japanese subjects. J Atheroscler Thromb. 2018;5:621-33.

16 Nagayama D, Watanabe Y, Saiki A, Shirai K, Tatsuno I. et al. Difference in positive relation between cardio-ankle vascular index (CAVI) and each of four blood pressure indices in real-world Japanese population. J Hum Hypertens. 2019;33(7):210-7. 
17 Nagayama D, Yamaguchi T, Saiki A, Imamura $\mathrm{H}$, Sato $\mathrm{Y}, \mathrm{Ban} \mathrm{N}$, et al. High serum uric acid is associated with increased cardio-ankle vascular index (CAVI) in healthy Japanese subjects: a cross-sectional study. Atherosclerosis. 2015;239:163-8.

18 Nakamura K, Tomaru T, Yamamura S, Miyashita Y, Shirai K, Noike H. Cardio-ankle vascular index is a candidate predictor of coronary atherosclerosis. Circ J. 2008;72:598604.

19 Sato Y, Nagayama D, Saiki A, Watanabe R, Watanabe Y, Imamura H, et al. Cardio-ankle vascular index is independently associated with future cardiovascular events in outpatients with metabolic disorders. J Atheroscler Thromb. 2016;23:596-605.

20 Nagayama D, Imamura H, Sato Y, Yamaguchi $\mathrm{T}$, Ban N, Kawana H, et al. Inverse relationship of cardioankle vascular index with BMI in healthy Japanese subjects: a cross-sectional study. Vasc Health Risk Manag. 2016;13:1-9.

21 Frühbeck G, Busetto L, Dicker D, Yumuk V, Goossens GH, Hebebrand J, et al. The ABCD of obesity: an EASO position statement on a diagnostic term with clinical and scientific implications. Obes Facts. 2019;12(2):131-6.

22 Mottillo S, Filion KB, Genest J, Joseph L, Pilote L, Poirier P, et al. The metabolic syndrome and cardiovascular risk a systematic review and meta-analysis. J Am Coll Cardiol. 2010;56:1113-32.

23 Nagayama D, Watanabe Y, Yamaguchi T, Maruyama M, Saiki A, Shirai K, et al. New index of abdominal obesity, a body shape index, is BMI-independently associated with systemic arterial stiffness in real-world Japanese population. Int J Clin Pharmacol Ther. 2020; 58(12):709-17.

24 Nagayama D, Endo K, Ohira M, Yamaguchi T, Ban N, Kawana H, et al. Effects of body weight reduction on cardio-ankle vascular index (CAVI). Obes Res Clin Pract. 2013;7: e139-45.

25 Liu H, Zhang X, Feng X, Li J, Hu M, Yambe T. Effects of metabolic syndrome on cardioankle vascular index in middle-aged and elderly Chinese. Metab Syndr Relat Disord. 2011;9(2):105-10.

26 Topouchian J, Labat C, Gautier S, Bäck M, Achimastos A, Blacher J, et al. Effects of metabolic syndrome on arterial function in different age groups: the Advanced Approach to Arterial Stiffness study. J Hypertens. 2018; 36(4):824-33.

27 Gomez-Sanchez L, Garcia-Ortiz L, PatinoAlonso MC, Recio-Rodriguez JI, Fernando R, Marti R, et al. Association of metabolic syndrome and its components with arterial stiffness in Caucasian subjects of the MARK study: a cross-sectional trial. Cardiovasc Diabetol. 2016;15(1):148.
28 Satoh N, Shimatsu A, Kato Y, Araki R, Koyama K, Okajima T, et al. Evaluation of the cardio-ankle vascular index, a new indicator of arterial stiffness independent of blood pressure, in obesity and metabolic syndrome. Hypertens Res. 2008;31(10):1921-30.

29 Krakauer NY, Krakauer JC. A new body shape index predicts mortality hazard independently of body mass index. PLoS One. 2012;7: e39504.

30 Christakoudi S, Tsilidis KK, Muller DC, Freisling $\mathrm{H}$, Weiderpass $\mathrm{E}$, Overvad $\mathrm{K}$, et al. A Body Shape Index (ABSI) achieves better mortality risk stratification than alternative indices of abdominal obesity: results from a large European cohort. Sci Rep. 2020;10(1): 14541.

31 Anoop S, Krakauer J, Krakauer N, Misra A. A body shape index significantly predicts MRIdefined abdominal adipose tissue depots in non-obese Asian Indians with type 2 diabetes mellitus. BMJ Open Diabetes Res Care. 2020; 8(1):e001324.

32 Liu J, Fan D, Wang X, Yin F. Association of two novel adiposity indicators with visceral fat area in type 2 diabetic patients: novel adiposity indexes for type 2 diabetes. Medicine. 2020;99(19):e20046.

33 Bertoli S, Leone A, Krakauer NY, Bedogni G, Vanzulli A, Redaelli VI, et al. Association of Body Shape Index (ABSI) with cardiometabolic risk factors: a cross-sectional study of 6081 Caucasian adults. PLoS One. 2017;12: e0185013.

34 Roberts WC. The Friedewald-Levy-Fredrickson formula for calculating low-density lipoprotein cholesterol, the basis for lipid-lowering therapy. Am J Cardiol. 1988;62:345-6.

35 Matsuo S, Imai E, Horio M, Yasuda Y, Tomita K, Nitta K, et al. Revised equations for estimated GFR from serum creatinine in Japan. Am J Kidney Dis. 2009;53(6):982-92.

36 Grundy SM, Brewer HB Jr, Cleeman JI, Smith SC Jr, Lenfant C; American Heart Association, et al. Definition of metabolic syndrome. Report of the National Heart, Lung and Blood Institute/American Heart Association conference on scientific issues related to definition. Circulation. 2004;109:433-8.

37 Youden WJ. Index for rating diagnostic tests. Cancer. 1950;3(1):32-5.

38 Itano S, Yano Y, Nagasu H, Tomiyama H, Kanegae H, Makino H, et al. Association of arterial stiffness with kidney function among adults without chronic kidney disease. Am J Hypertens. 2020;33(11):1003-10.

39 Tomiyama H, Yamashina A. Non-invasive vascular function tests: their pathophysiological background and clinical application. Circ J. 2010;74:24-33.
40 Juonala M, Viikari JS, Laitinen T, Marniemi J, Helenius $\mathrm{H}$, Rönnemaa $\mathrm{T}$, et al. Interrelations between brachial endothelial function and carotid intima-media thickness in young adults: the cardiovascular risk in young Finns study. Circulation. 2004;110(18):2918-23.

41 Sugiura T, Dohi Y, Takagi Y, Yoshikane N, Ito M, Suzuki K, et al. Relationships of obesityrelated indices and metabolic syndrome with subclinical atherosclerosis in middle-aged untreated Japanese workers. J Atheroscler Thromb. 2020;27(4):342-52.

42 Yue M, Liu H, He M, Wu F, Li X, Pang Y, et al. Gender-specific association of metabolic syndrome and its components with arterial stiffness in the general Chinese population. PLoS One. 2017;12(10):e0186863.

43 Shi TH, Wang B, Natarajan S. The influence of metabolic syndrome in predicting mortality risk among US adults: importance of metabolic syndrome even in adults with normal weight. Prev Chronic Dis. 2020;17:E36.

44 Moore SC. Waist versus weight: which matters more for mortality? Am J Clin Nutr. 2009; 89:1003-4.

45 Ofstad AP, Sommer C, Birkeland KI, Bjørgaas MR, Gran JM, Gulseth HL, et al. Comparison of the associations between non-traditional and traditional indices of adiposity and cardiovascular mortality: an observational study of one million person-years of follow-up. Int J Obes. 2019;43(5):1082-92.

46 Otsuka K, Fukuda S, Shimada K, Suzuki K, Nakanishi K, Yoshiyama M, et al. Serial assessment of arterial stiffness by cardio-ankle vascular index for prediction of future cardiovascular events in patients with coronary artery disease. Hypertens Res. 2014;37(11): 1014-20.

47 Park Y, Kim NH, Kwon TY, Kim SG. A novel adiposity index as an integrated predictor of cardiometabolic disease morbidity and mortality. Sci Rep. 2018;8(1):16753

48 Song X, Jousilahti P, Stehouwer CD, Söderberg S, Onat A, Laatikainen T, et al. Cardiovascular and all-cause mortality in relation to various anthropometric measures of obesity in Europeans. Nutr Metab Cardiovasc Dis. 2015;25(3):295-304.

49 Matsushita Y, Nakagawa T, Yamamoto S, Takahashi Y, Yokoyama T, Noda M, et al. Associations of visceral and subcutaneous fat areas with the prevalence of metabolic risk factor clustering in 6,292 Japanese individuals: the Hitachi Health Study. Diabetes Care. 2010;33(9):2117-9.

50 Bawadi H, Abouwatfa M, Alsaeed S, Kerkadi A, Shi Z. Body shape index is a stronger predictor of diabetes. Nutrients. 2019;11(5): 1018. 